\title{
Ecologies-A New Multidisciplinary and International Open Access Journal
}

\author{
José Ramón Arévalo \\ Department of Botany, Ecology and Plant Physiology, University of La Laguna, 38206 La Laguna, Spain; \\ jarevalo@ull.edu.es
}

Received: 2 July 2020; Accepted: 2 July 2020; Published: 10 July 2020

As we head towards the middle of the 21st century, environmental problems become more evident in our planet, in part because of the human pressure on natural resources and also because of the concern of humans about this damage, requiring more specific tools for the evaluation of the negative impacts of human activities, and also the development of restoration tools to confront these problems. The field of ecology today is a perfectly established field of science and its demand has grown continuously.

In this context I am glad to have the honor to be the first editor and announce the launch of this new journal with the attractive name Ecologies. The name itself reflects, in some way, both the scope of the journal and our vision for the journal's future-to serve as an international, multidisciplinary, general and ambitious scholarly journal of high quality competing with journals of the same field. The field of ecology, an established field of science that some authors suggest started with Linneo (18th century), some others with Aristotle (4th century B.C.), but many agree that the formal foundation took place with the author that popularized the word "Ecology", Ernst Haeckel in the 19th century [1].

The requirement of ecological studies able to understand the relationships among biota and biotope are a fundamental step to analyze the situation and suggest changes, restorations or other proposals of interest based on scientific information. The speculation, although very popular in the last few decades in the field of ecology, is not an option for academics and scholars willing to generate scientific proposals to protect the environment and conserve populations and communities.

Ecologies will be a free tribune to confront and present scientific information of interest for an international readership, requiring the highest standards of quality as long as the journal pretend to be positioned as a reference in the field of ecology. The launch of a new journal is always a risk, but it is also a risk to reject an opportunity to have a new way to present ecological results. As it was written 100 years ago: "A general journal of Ecology which should bring together current work had become an urgent need of all the students of the subject, owing the enormously increased and increasing output of ecological publication" [2].

Maybe you are asking, why another journal about ecology? There are more than 160 journals enclosed in the category of "Ecology" (Clarivate Analytics), some of them with an IF>10, and a few of them with more than 100 years of presence in the academic environment. We still believe there is room for another good quality journal, as in the last 20 years there has been a great pressure on researchers to publish in indexed journals. As long as the space is limited, there is great chance good papers are never published because of that. On the other hand, many of these important journals have a core of a few researchers and an international association that basically promotes the publication of their own members.

The aim of this open access journal is to provide a forum to present results and ideas and debate issues related to general ecology. Ecologies will publish the results of original research, reviews, short communications, and commentaries. Since there is no restriction on paper length, detailed experimental data and methods can be presented. We will also promote Special Issues, which provide more detailed 
information of specific fields in ecology. The editorial board has broad expertise covering most aspects of Ecology: plant ecology, animal ecology, marine ecology, theoretical ecology, microbial ecology, etc. The success of this endeavor will depend upon the research community and we, therefore, hope you will actively participate by submitting high quality papers to Ecologies, provide suggestions of Special Issues and give general feedback on the objectives and progress of this journal. In addition, it will have all the advantages of open access journals-most importantly a fast review process and reasonable publication costs for authors, and free access for all.

You can consider your contributions in the following way:

1. Submit articles yourself-original research results, surveys, reviews, or letters.

2. Consider opportunities and topics for Special Issues, especially some major advances in your research field, which could form the basis for a Special Issue.

As predicted by Barrington Moore 100 years ago, biological sciences and the present environmental problems demand research which is fundamentally ecological in character, and this demand will grow in the future [3]. We are glad to say that Moore was correct and, 100 years later, the demand continues growing and requires publicity through scientific journals.

Although it was long ago, his words remain alive at the highest level: "Will we be content to remain zoolgists, botanists and foresters, with little understanding of one another's problems, or will we endeavor to become ecologist in the broad sense of the term? The part we play in science depends upon our reply. Gentlemen, the future is in our hands."

We are looking forward and waiting for your submissions, your suggestions for new Special Issues, and your support for this new journal that we expect will soon become a reference in Ecology.

Conflicts of Interest: The authors declare no conflict of interest.

\section{References}

1. Deléage, J.P. Histoire de l'Écologie; La Découverte: Paris, France, 1991.

2. Tansley, A.G. The aims of the new journal. J. Ecol. 1913, 1, 1-4.

3. Moore, B. The scope of Ecology. Ecology 1920, 1, 3-5. 